\title{
Sobre os autores dos originais em alemão: Albert Kruse, Dascha Detering e Gottfried Polykrates
}

\author{
Marcos Antonio de Almeida* \\ Roberto Soares de Oliveira * * \\ Adriana Russi*** \\ Astrid Keiffer-Døssing****
}

\begin{abstract}
ALMEIDA, M.A. OLIVEIRA, R.S. RUSSI, A. KEIFFER-DØSSING, A. Sobre os autores dos originais em alemão: Albert Kruse, Dascha Detering e Gottfried Polykrates. R. Museu Arq. Etn. 37: 28-30, 2021.
\end{abstract}

Resumo: Neste capítulo, foram reunidas as informações gerais sobre o frei Albert Kruse, autor de dois dos oito textos traduzidos no Dossiê; Gottfried Polykrates, que escreveu seis textos traduzidos neste volume; e Dascha Detering, a única mulher autora de um dos originais em alemão desta publicação.

Palavras-chave: Albert Kruse; Gottfried Polykrates; Dascha Detering; Biografia; Autores europeus.

\section{Frei Albert Kruse (1892-1956}

\section{Por Fr. Marcos Antonio de Almeida e} Fr. Roberto Soares de Oliveira

Frei Albert Kruse nasceu aos 16 de junho de 1892, em Paderborn, Alemanha. Ele faleceu no Hospital do Serviço Especial de Saúde Pública (Sesp), em Santarém/PA, em 1956. Foi batizado com o nome de Joseph, e após o estudo ginasial, em 5 de maio de 1910, em Warendorf, recebeu o hábito franciscano e iniciou o noviciado. Naquele mesmo ano, dom Amando Bahlmann (1862-1939), bispo

\footnotetext{
* Membro do Arquivo Provincial Franciscano do Recife. <malmeida11@hotmail.com>

** Diretor do Arquivo Provincial Franciscano do Recife. <apfrecife@gmail.com>

*** Docente da Universidade Federal Fluminense e do Programa de Pós-Graduação em Memória Social da Unirio. <adri.russitm@gmail.com>

**** Doutoranda da Universidade de Aarhus. <astridkieffer@gmail.com>
}

da Prelazia de Santarém, no Pará (1907-1939), visitou o convento e apresentou tal Prelazia com seus desafios e necessidades. Como havia carência de sacerdotes, sua conferência se transformou num convite aos jovens noviços, dentre os quais estava o jovem Albert Kruse. Aos 6 de maio de 1911, frei Albert Kruse fez sua Profissão Simples e, após as devidas permissões de sua província, embarcou para o Brasil - seu tio, Dom Miguel Kruse (18641929), foi abade do mosteiro de São Bento (1908), em São Paulo/SP -, onde chegou aos 30 de maio daquele mesmo ano. Suas atividades missionárias se realizaram no Pará durante toda sua vida no Brasil.

Seria necessário um tempo mais longo para construir sua trajetória evangelizadora e sua contribuição para a formação do Norte do Brasil. Kruse ficou doente, foi medicado e recebeu toda a atenção possível, porém não resistiu. Recebeu os sacramentos às vésperas do Natal, às $11 \mathrm{~h} 45$, no dia 24 de dezembro de 1956, e expirou 
dizendo: "Meu Jesus, misericórdia!" (Província Franciscana de Santo Antônio do Brasil 1987: 8791). Ele faleceu no Hospital do Serviço Especial de Saúde Pública (Sesp), em Santarém/PA. A missa de corpo-presente e exéquias foram assistidas por dom Floriano Loewenau (1912-1979), bispo da Prelazia de Óbidos (Vieira 2018), e por seus irmãos franciscanos presentes naquele momento.

\section{Dascha Detering (1911-2006)}

Por Adriana Russi $i^{2}$

A desenhista Dascha Detering trabalhou por muitos anos como artista gráfica científica para o Museu Völkerkunde, na cidade de Hamburgo, na Alemanha. Nascida em 1911 em Kiev, Ucrânia, imigrou para a Alemanha, onde tornou-se pintora e artista gráfica. No museu, trabalhou como uma importante artista científica profissional, fazendo desenhos detalhados de objetos para os "cartões" de identificação dos artefatos do inventário do museu. Ela teve especial interesse pelo tema da cestaria indígena, como revela seu artigo "Trançados e técnicas de entretrançado dos índios Kaschuyana do Nordeste do Brasil”, de 1962, incluído nesta coletânea. Faleceu em 10 de junho de 2006. Há um pequeno artigo sobre a vida e o trabalho de Dascha Detering no museu, escrito por Anke Blanck (2007).

\section{Gottfried Polykrates (1927-?)}

Por Astrid Keiffer-Døssing

Gottfried Polykrates nasceu na Grécia, em 1927, era alpinista e instrutor no exército grego de técnicas de guerra realizadas em períodos de inverno. Nutria grande interesse

2 Este texto foi produzido a partir de dados extraídos de entrevista realizada em 2013 com Christine Chavez, na ocasião curadora do Departamento das Américas no então denominado Volkerkund Museum, hoje Museum am Rothenbaum Kulturen und Künste der Welt (MARKK), em Hamburgo, Alemanha. pela pré-história da Grécia. Após o término da Guerra Civil na Grécia, Polykrates chegou à Dinamarca, onde viveu de 1952 a 1969. Nesse período, realizou várias viagens como etnógrafo amador, e em cinco delas visitou indígenas na floresta amazônica.

Na primeira expedição, em 1957, Polykrates e o dinamarquês Christen Søderberg, também etnógrafo amador, visitaram duas aldeias do povo Katxuyana, uma no rio Trombetas e outra no rio Cachorro. Após seu retorno à Dinamarca, Christen Søderberg fez descrições dos objetos coletados na expedição. A maioria deles foi comprada com recursos concedidos pela Fundação Consul George Jorck e esposa Emma Jorck, e entre os objetos remanescentes, grande parte foi comprada pelo Museu Britânico, em Londres.

Na segunda expedição, que ocorreu entre 1958 e 1959, Polykrates viajou da Guiana Inglesa para o Brasil junto com Jens Yde, que na época era curador das Américas no Museu Nacional da Dinamarca. Eles visitaram aldeias dos povos Waiwai, Hixkaryana, Xeréo e Katxuyana.

Após a segunda expedição, Polykrates vendeu uma série de objetos coletados para o Museu de História Cultural em Oslo, Noruega. Ele editou um filme com gravações de ambas as expedições, cuja estreia na Dinamarca ocorreu no início dos anos 1960.

Além disso, Polykrates também escreveu uma série de artigos sobre os Katxuyana, abordando festividades religiosas, a criação do mundo e outros mitos, pinturas faciais e corporais, bem como a cultura material. Esses artigos foram publicados em revistas de divulgação científica em dinamarquês, e os textos que escreveu sobre os Katxuyana em alemão fazem parte deste Dossiê.

Ele também publicou livros baseados em observações de suas viagens à América do Sul. Entre eles está Puragudens folk (Polykrates 1963), obra publicada em dinamarquês que registra inúmeros aspectos do povo Katxuyana e de outros indígenas, cujo título numa tradução livre em português seria "O povo do Deus Pura”. Também em dinamarquês, publicou Medicinmandens hæun (1966), ou "A vingança 
Sobre os autores dos originais em alemão: Albert Kruse, Dascha Detering e Gottfried Polykrates

R. Museu Arq. Etn., 37: 28-30, 2021.

do curandeiro". Polykrates também escreveu sobre o povo Yanomami em textos publicados em alemão: Wawanaueteri und Pukimapueteri Zwei Yanonami-Stämme Nordwestbrasiliens (1969), em tradução livre, "Duas Tribos Yanomami do Noroeste do Brasil”, e Beiträge zur Religionsfrage der Yanomami-indianer (1974), que em português poderíamos traduzir como "Contribuições para as questões religiosas dos índios Yanomami”.
Paralelamente às viagens para a América do Sul, Polykrates também realizou outras expedições de caráter "semicientífico" enquanto vivia na Dinamarca. Essas expedições o levaram a países como Camarões, Líbia, Etiópia, Ruanda, Burundi, Zanzibar, Tanzânia e Bahrein. Polykrates terminou sua carreira como viajante em 1971, alguns anos depois de ter se mudado para a Áustria com sua família.

ALMEIDA, M.A. OLIVEIRA, R.S. RUSSI, A. KEIFFER-DøSSING, A. About the authors of the originals in German: Albert Kruse, Dascha Detering, and Gottfried Polykrates. R. Museu Arq. Etn. 37: 28-30, 2021.

Abstract: This chapter gathers general information on Fr. Albert Kruse, author of two of the eight texts translated in the Dossier; Gottfried Polykrates, author of six of the translated texts; and Dascha Detering, the only woman who authored one of the originals in German translated here.

Keywords: Albert Kruse; Gottfried Polykrates; Dascha Detering; Biography; European authors.

\section{Referências bibliográficas}

Blanck, A. 2007. Eine Künstlerin in der Völkerkunde - Dascha Detering (31.12.1911 - 10.06.2006). In: Köpke, W.; Schmelz, B. (eds.). Mit Kamel und kamera: historische Orient-Fotografie 1864-1970 (Mensagens do Museu de Etnologia). Neu Folge, Hamburgo, v. 38, 723727.

Polykrates, G. 1963. Puragudens folk. Hernov, Copenhagen.

Polykrates, G. 1966. Medicinmandens hoevn. Aller, Copenhagen.

Polykrates, G. 1969. Wawanauteri und Pukimapueteri: zwei Yanonami-Stämme Nordwestbrasiliens.
Publications of the National Museum of Denmark, Copenhagen.

Polykrates, G. 1974. Beiträge zur Religionsfrage der Yanonámi-Indianer. Aarhus Universitetsforlag, Aarhus.

Província Franciscana de Santo Antônio do Brasil. 1957. Necrológio de Frei Albert Kruse. Revista Santo Antônio ano 15: 8791.

Vieira, C.A.S. 2018. Vida e obras, legado de Dom Floriano Loewenau, $1^{\circ}$ bispo prelado de Óbidos. Disponível em: <https://bit.ly/2WlA09J>. Acesso em 4 mar. 2021. 